\title{
Thermo-mechanical Coupled Simulation Analysis of Solid End Mill on
}

\section{Milling Process}

\author{
YanCAO, XinhuLIU, LeijieFU, YuBAI \\ (School of Mechatronic Engineering, Xian Technological University, Xian 710032 China) \\ E-mail: jantonyz@163.com
}

\begin{abstract}
In the milling process, the temperature and milling force have an important influence on tool life, so the prediction of the thermo-mechanical coupling field is very important. According to the actual cutting characteristics of solid carbide end milling cutter for processing T10 carbon tool steel, the heat flux and milling force transferred to the end mill during milling process were calculated. The simulation analysis was carried out by orthogonal experiment method and large-scale finite element software ANSYS. The simulation results showed that the situation of Thermo-Mechanical Coupled Simulation about the end millunder different machining conditions (cutting depth, feed per tooth, cutting width, etc.), and the variation rule of the cutter is analyzed and predicted. The results showed that with the change of cutting depth, feed rate and cutting width, the maximum equivalent stress of the end milling cutter changed in certain laws, and the higher equivalent stress located at cutting edge.
\end{abstract}

Keywords: end mill; milling force; thermo-mechanical coupling; heat flux; ANSYS

\section{Introduction}

In milling process, milling forces and milling temperature are important factors which influence tool wear and breakage. A lot of heat is generated in milling process, such as the energy consumed by elastic and plastic deformation, chip separation and friction is converted into heat energy, and only a few of energy is converted into other potential energy forms. Thus, in the course of the study, we consider that the energy, which consumed in the cutting process, all converted into heat energy. The heat generated during the milling process and the corresponding milling force may cause the plastic deformation of the end mill, and reduce the machining accuracy of the workpiece. At present, the change of temperature and deformation of structure of the end mill during the high-speed milling process is the important subject. Therefore, it is important to study the influence of the thermo-mechanical coupling field on the solid carbide end mill during the milling process, which is an important guarantee to predict the damage of the carbide end mill and improve the machining precision. This study analyzed the thermo-mechanical coupling by ANSYS to study the interaction of temperature and structure of end milling cutter in milling.

\section{Thermo-mechanical coupled simulation analysis of solid end mill on milling process}

\subsection{Calculation of milling force and instantaneous heat flux in milling}

According to the power calculation formula of $P=F^{*} v$, the instantaneous power of the tool in milling requires a corresponding force and rate. In the milling process, it is assumed that all the work done by the tool all converted to heat, mainly including the heat which generated by shear deformation and friction.

This study used carbide alloy cylindrical end mill, selected the carbon steel for the processing work piece and used the milling force empirical formula of the end milling cutter to calculate[1].

$$
F_{c}=9.81(96.6) a_{e}^{0.88} f_{z}^{0.75} a_{p} z d_{0}^{-0.87}
$$


Query related literature

$$
\begin{aligned}
& F_{r} \approx(0.80 \sim 0.90) F_{c} \\
& F_{p} \approx(0.35 \sim 0.4) F_{c}
\end{aligned}
$$

Where $F_{c} \longrightarrow$ tangential milling force $(\mathrm{N})$

$F_{r} \longrightarrow$ radial milling force $(\mathrm{N})$

$F_{p} \_$axial milling force $(\mathrm{N})$

$a_{p} \longrightarrow$ milling depth (mm)

$d_{0}$ cutter diameter $(\mathrm{mm})$

$z-$ tooth number of cutter

$f_{z} \longrightarrow$ Feed per tooth $(\mathrm{mm} / \mathrm{z})$

According to the tangential milling force, the size of the shear force $\left(F_{S}\right)$ can be obtained, the correlation formula is as follow[2]:

$$
F_{S}=\frac{2 F_{c}}{\cos \theta\left(1+l_{1} / L\right)}
$$

The size of the friction force of the tool is $F_{a}$

$$
F_{a}=\mu F_{r}
$$

Where $\theta-$ tool helix angle

$L-$ knife - chip contact length

$l_{1} \_$knife - chip tight contact area length

$\mu-$ friction coefficient

During the right-angle milling process, the relationship between cutting speed $v$, shear velocity $v_{s}$ and chip flow velocity $v_{a}$ is as follow[3]:

$$
v=v_{a}-v_{s}
$$

The decomposition of each cutting speed to the corresponding coordinate axis,

$$
\begin{gathered}
v-v_{a} \sin \gamma_{0}-v_{s} \cos \phi_{c}=0 \\
v_{s} \sin \phi_{c}-v_{a} \cos \gamma_{0}=0
\end{gathered}
$$

Where $\gamma_{0} \longrightarrow$ tool rake angle

$\phi_{c} \longrightarrow$ shear angle.

The size of shear speed $v_{s}$ and chip flow velocity $v_{a}$ can be obtained from the above two formulas. 
The instantaneous power of end mill in milling[4]

$$
P=F_{S} * v_{s} * R_{\xi}+F_{a} * v_{a}
$$

$R_{\xi}$ The energy ratio that is passed into the tool

\subsection{Load calculation}

In this study, we used the coupling analysis functionsof finite element analysis software ANSYS to analysis and predict the changes of cutter internal Thermo-mechanical coupling field distribution under different high-speed machining conditions. The orthogonal experimental design was used to do a three-factor and three-level experimental analysis, three factors were cutting depth $a_{\mathrm{p}}(1 \mathrm{~mm} 、 2 \mathrm{~mm} 、 3 \mathrm{~mm})$, feed per tooth $f_{\mathrm{z}}$ $(0.05 \mathrm{~mm} 、 0.10 \mathrm{~mm} 、 0.20 \mathrm{~mm})$, cutting width $a_{\mathrm{e}}(0.40 \mathrm{~mm} 、 0.45 \mathrm{~mm} 、 0.50 \mathrm{~mm})$, respectively. The load was calculated as follows.

The cutting condition parameters are shown in Table 1.

Table 1 Cutting conditions parameters

\begin{tabular}{cccccccc}
\hline $\begin{array}{c}\text { Workpiece } \\
\text { material }\end{array}$ & $\begin{array}{c}\text { Tool } \\
\text { material }\end{array}$ & $\begin{array}{c}\text { Number } \\
\text { of tool } \\
\text { teeth }\end{array}$ & $\begin{array}{c}\text { Tool } \\
\text { diameter }\end{array}$ & $\begin{array}{c}\text { Rake } \\
\text { angle }\end{array}$ & $\begin{array}{c}\text { Helix } \\
\text { angle }\end{array}$ & $\begin{array}{c}\text { Cutting } \\
\text { conditions }\end{array}$ & $\begin{array}{c}\text { Spindle } \\
\text { speed } v\end{array}$ \\
\hline $\begin{array}{c}\text { T10Carbon tool } \\
\text { steel }\end{array}$ & Carbide & 4 & $8 \mathrm{~mm}$ & $12^{\circ}$ & $32^{\circ}$ & $\begin{array}{c}\text { Dry cutting, } \\
\text { reverse } \\
\text { milling }\end{array}$ & $3000 \mathrm{r} / \mathrm{min}$ \\
\hline
\end{tabular}

According to L9 (3) orthogonal table arrangement experiment, the load of the end milling cutter is shown in Table 2 .

Table 2 The load of the end mill under different cutting parameters

\begin{tabular}{|c|c|c|c|c|c|c|c|}
\hline $\begin{array}{l}\text { Serial } \\
\text { number }\end{array}$ & $a_{\mathrm{p}}$ & $f_{\mathrm{z}}$ & $a_{\mathrm{e}}$ & $F_{c}$ & $F_{r}$ & $F_{p}$ & $P$ \\
\hline 1 & 1.00 & 0.05 & 0.40 & 29.31 & 23.45 & 10.26 & 23.83 \\
\hline 2 & 1.00 & 0.10 & 0.45 & 54.68 & 43.74 & 19.14 & 44.46 \\
\hline 3 & 1.00 & 0.20 & 0.50 & 100.90 & 80.72 & 35.32 & 82.04 \\
\hline 4 & 2.00 & 0.05 & 0.45 & 65.03 & 52.02 & 22.76 & 52.88 \\
\hline 5 & 2.00 & 0.10 & 0.50 & 120.00 & 96.00 & 42.00 & 97.57 \\
\hline 6 & 2.00 & 0.20 & 0.40 & 165.80 & 132.64 & 58.03 & 134.81 \\
\hline 7 & 3.00 & 0.05 & 0.50 & 107.02 & 85.62 & 37.46 & 87.02 \\
\hline 8 & 3.00 & 0.10 & 0.40 & 147.90 & 118.32 & 51.77 & 120.26 \\
\hline 9 & 3.00 & 0.20 & 0.45 & 275.90 & 220.72 & 96.57 & 224.34 \\
\hline
\end{tabular}




\subsection{Thermo-mechanical coupled analysis of solidend mill based on ANSYS}

Firstly, we need to create a 3D end mill model with SolidWorks and save it in the $x_{-} t$ format. Then, import the 3D model of end mill into ANSYS software. Here, SOLID98 three-dimensional coupled field solid element is selected to mesh the integral end mill.

All of the analysis of the ANSYS need the parameters of the material properties, the specific parameters of the material properties about the end milling cutter see table 3

Table 3 Carbide material properties

\begin{tabular}{|c|c|c|c|c|c|c|}
\hline $\begin{array}{l}\text { Material } \\
\text { name }\end{array}$ & $\begin{array}{c}\text { Elastic } \\
\text { modulus } E \\
\qquad \mathrm{GPa}\end{array}$ & $\begin{array}{c}\text { Poisson ratio } \\
v\end{array}$ & $\begin{array}{c}\text { Thermal } \\
\text { conductivity } \\
K \\
\mathrm{~W} /(\mathrm{m} * \mathrm{~K})\end{array}$ & $\begin{array}{c}\text { Coefficient } \\
\text { of thermal } \\
\text { expansion } \alpha \\
10^{-6} /{ }^{\circ} \mathrm{C}\end{array}$ & $\begin{array}{c}\text { Density } \rho \\
\mathrm{kg} / \mathrm{m}^{3}\end{array}$ & $\begin{array}{c}\text { Specific heat } \\
c \\
\mathrm{~J} /\left(\mathrm{kg} *^{\circ} \mathrm{C}\right)\end{array}$ \\
\hline Carbide & 635 & 0.3 & 79.55 & 4.6 & 14.5 & 209.3 \\
\hline
\end{tabular}

Setting the grid division level. the accuracy of grid division directly determines the quality of the finite element calculation. In general,finer meshing and higher accuracy of the calculation could expend more computer resources. For the helical part of the end mill, its structure is more complex,so it is the main part of the thermo-mechanical coupling to be analyzed and needed to be fine-grained.

According to the actual loading condition of flat-bottomed milling cutter to determinethe boundary condition. and the constraint condition of the solid carbide end milling cutter is fully restrained:ALL DOF, ambient temperature is $20^{\circ} \mathrm{C}$, The natural convection heat exchange is provided in the part where the tool is in contact with the air, the natural convection coefficient of air is $10 \mathrm{~J} /\left(\mathrm{m} 2 \cdot \mathrm{s} \cdot{ }^{\circ} \mathrm{C}\right)$, outside temperature is $20^{\circ} \mathrm{C}$. Clamping part of the handle is constant temperature boundary, the constant temperature value $20^{\circ} \mathrm{C}$.

In the integral end milling process, the end milling cutter can be regarded as a revolving movement, here we can calculate the heat, the heat transferred to the cutting tool and the corresponding simplified calculation of the milling force by each turn of the tool, and then loaded into the finite element model of the end mill by a "do" loop, the finite element analysis can make it reach a stable state. After many times of cyclic loading, the result of the thermo-mechanical coupling analysis can be viewed by postprocessing of the results. Figure 1 shows the equivalent stress model for end mills.

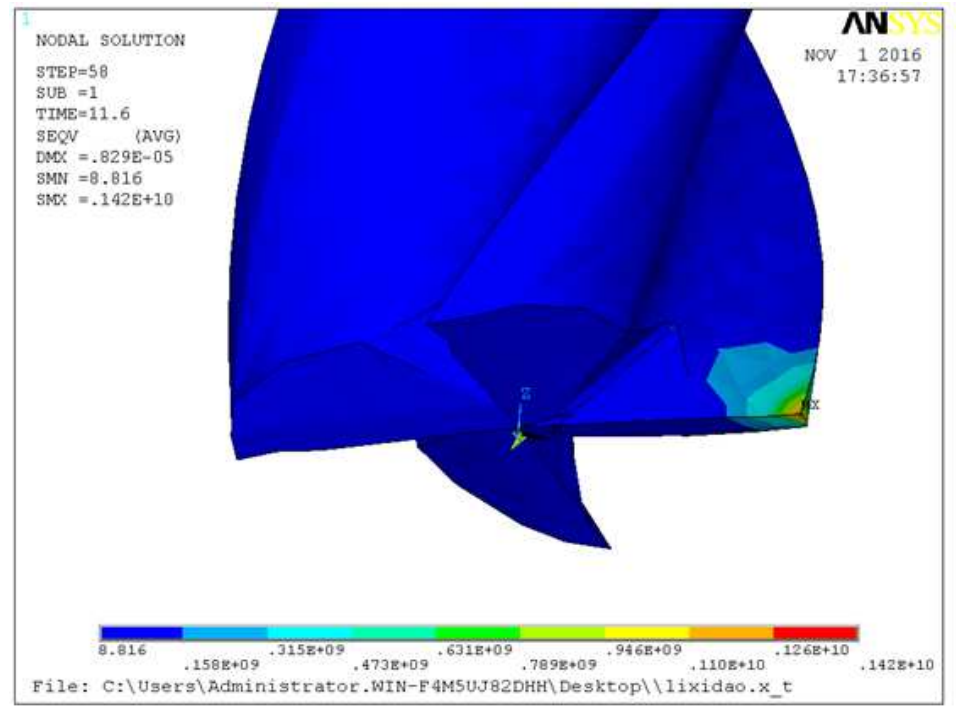

Fig.1 Equivalent stress diagram of end mill

Next, we need to calculate the different load parameters of other cutting parameters, and the method is same as before, the final thermo-mechanical coupling model of the end mill with different cutting parameters is shown in Fig.2. 

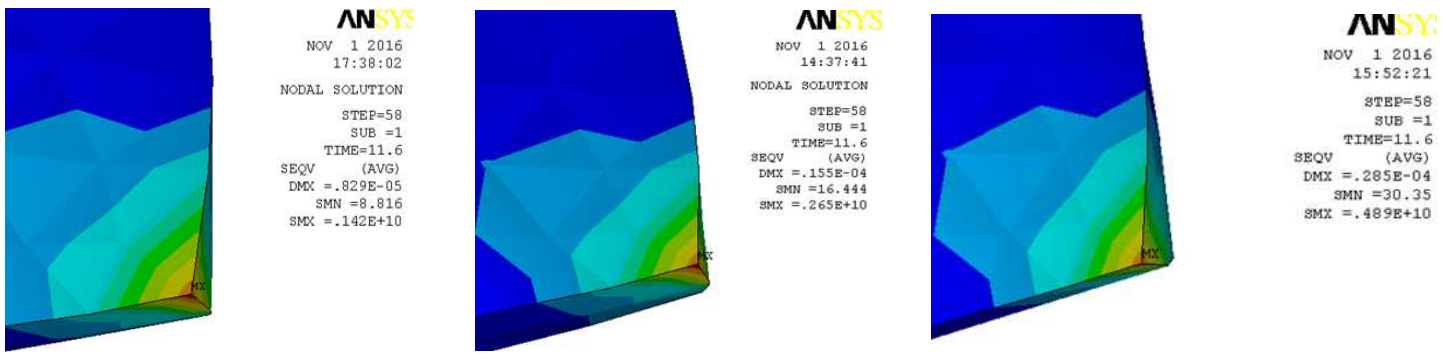

1

2
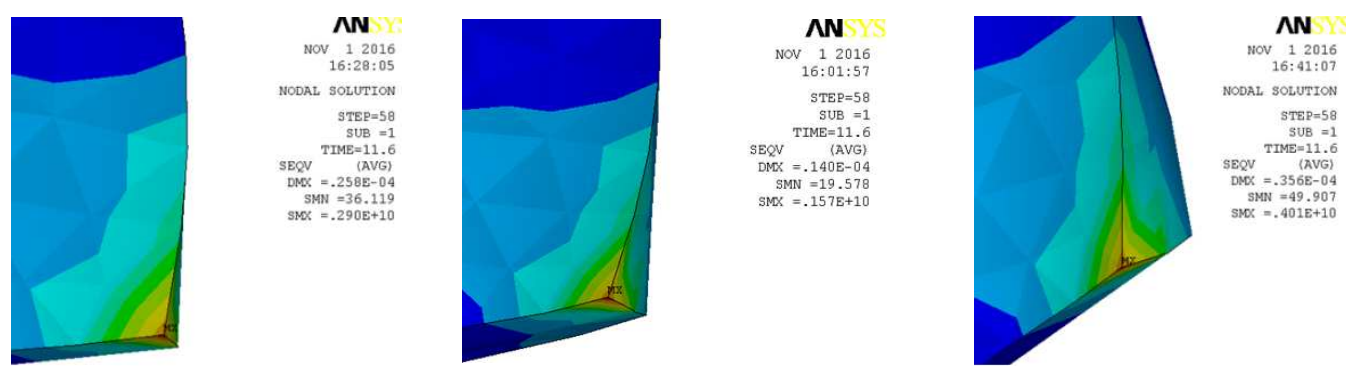

5
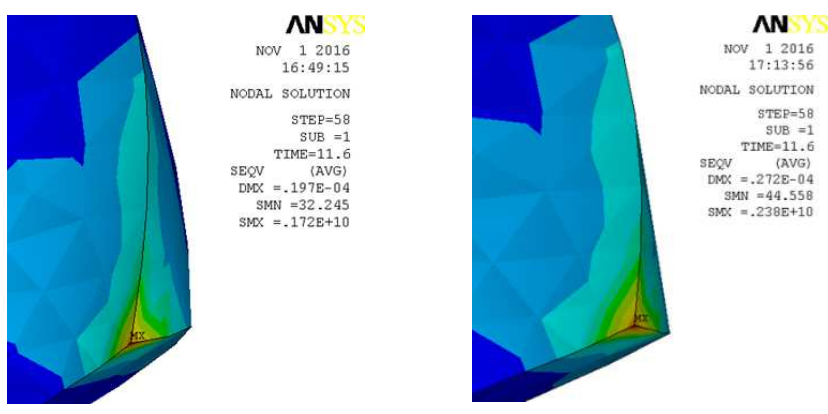

7

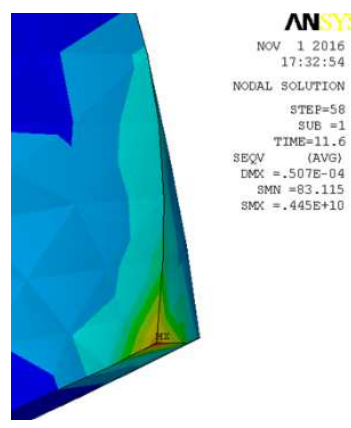

8

Fig.2 Equivalent stress plots of end mills under different cutting parameters

\section{Analysis of calculation results}

The load calculated from different cutting conditions is applied to the end mill, the maximum equivalent stress obtained after ANSYS calculation is plotted in Fig 3.

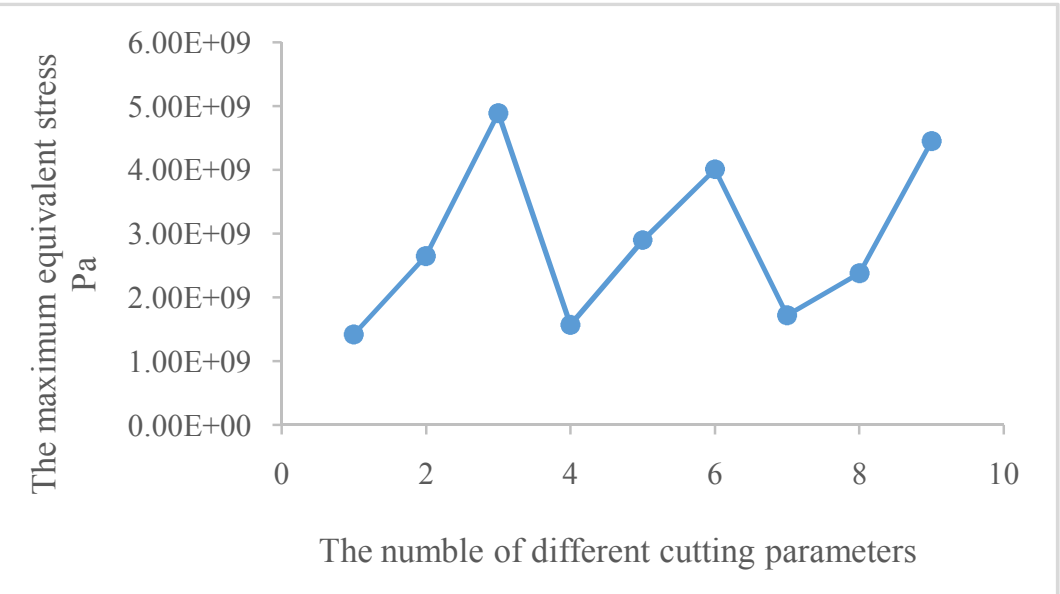

Fig.3 Relationship between different cutting parameters and maximum equivalent stress 
According to the obtained relational graph, the maximum equivalent stress of the tool is taken as the optimization target of the analysis, and the following conclusions are drawn.

According to orthogonal experimental design method to select the corresponding cutting parameters, calculate the different load conditions for simulation analysis, the maximum equivalent stress linear curve of the end mill cutter is obtained, and the large equivalent stress is located at the cutting edge. It can be seen from the figure in the high-speed machining of carbon steel carbide by the solid end mill, the maximum equivalent stress of the simulation parameters corresponding to No.1, No.4 and No.7 is relatively small, and considering its processing efficiency and chip removal rate, while understanding the impact of the degree of performance of the tool and its processing materials by the temperature, referring to the above analysis of the different cutting the equivalent stress value, select the corresponding cutting parameters of 7 is more reasonable.

\section{Conclusion}

In this study, the milling force and power of the end mill in the milling process under various high-speed machining conditions (cutting depth, feed per tooth, cutting width, etc.) were acquired through the heat source method, the finite element software ANSYS was used to simulate the thermo-mechanical coupling field distribution of the end mill, the analysis results of different processing conditions were compared and the corresponding relations between the cutting parameters and the maximum equivalent stress in the stable milling of the cutter were obtained, which provide the theoretical basic for the change of the equivalent stress of the solid carbide end mills in the actual processing of carbon steel workpiece, and improve the life cycle of the end mills, it provides a theoretical basic for the failure analysis and optimization design of the end mills Milling cutter structure.

\section{Acknowledgments}

The research of this paper is supported by the special processing Key Laboratory of Shaanxi province (15JS041) and the Shaanxi Provincial Education Department (16JK1388).

\section{References}

[1] Yao Du. Finite Analysis of Solid Carbide End Milling Cutter [D]. Chengdu: Xihua University, 2010.

[2] M A Younis. Mechanical and Thermal Stresses in Clamped, Brazedand Bonded Carbide Tools[J]. Journal of Engineering for Industry, 1992, 114(4): 337-385.

[3] Guangyu Tan, Qingshan Liu, Can Liu, Guanghui Li, Jingquan Wu. Analysis Modeling of Cutting Force in High-speed Milling Process for Flat End Mill [J]. Mechanical Science and Technology for Aerospace Engineering, 2012, 31(11): 1735-1739.

[4] Wei Bo, Guangyu Tan, Linlin Guo, Guanghui Li. Research on Dynamic Temperature Field Modeling of the Solid CarbideEnd Milling High-speed Milling[J]. Advanced Materials Research, 2015, 1089: 350-353. 